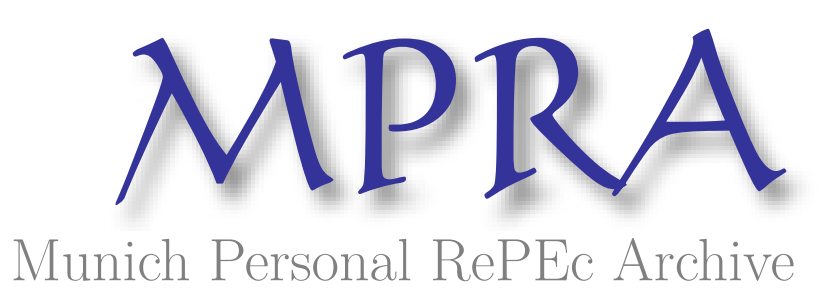

\title{
Oligopolistic Competition and Economic Geography
}

Zhou, Haiwen

8 September 2018

Online at https://mpra.ub.uni-muenchen.de/88919/

MPRA Paper No. 88919, posted 15 Sep 2018 07:47 UTC 


\title{
Oligopolistic Competition and Economic Geography
}

\author{
Haiwen Zhou
}

\begin{abstract}
This paper studies a general equilibrium model of economic geography in which firms engage in oligopolistic competition. This framework is conducive to analytic results. With increasing returns, oligopolistic competition leads to inter-industry trade between regions rather than intra-industry trade. The choice of appropriate technology is a channel of concentration of industries.
\end{abstract}

Keywords: Oligopolistic competition, economic geography, increasing returns to scale, choice of technology, inter-industry trade

JEL Classification Numbers: F12, F20, R10

I thank Anne M. Alexander, Marlon G. Boarnet, Robert W. Godby, Michael Moore, Steven Suranovic, Yanling Wang, Zhihao Yu, and seminar participants at the Carleton University and the University of Wyoming for their valuable comments. Detailed and insightful comments from two anonymous referees and the inspiration from Neary (2001) are highly appreciated. The usual disclaimer applies. 


\section{INTRODUCTION}

In his famous book, Porter (1990) argues that concentration of firms producing similar products in given regions is a common phenomenon rather than exceptional. Issues related to the location choices of firms are interesting to both regional and national governments trying to keep current and seeking new business opportunities. Krugman (1991) has studied a model of economic geography based on monopolistic competition. Many useful insights have emerged from this line of literature. However, as discussed in Neary (2001) and Head and Mayer (2004), there are some well-recognized limitations of the monopolistic competition approach. First, strategic interaction among firms is absent. Second, with the constant elasticity substitution utility function, a firm's output is independent of the size of the market. For monopolistic competition models, trade changes the number of varieties, rather than scales of production. As increasing returns to scale is strongly emphasized in the "new economic geography", it is important to study how a firm's scale of production changes with the fundamentals.

For the monopolistic competition approach, it is assumed that new varieties are always freely available. With this assumption, a firm always prefers to produce a product different from existing ones to avoid competition with other firms. In reality, new varieties may be obtained only through very costly research and development effort. In this paper, it is assumed that the number of varieties in the manufacturing sector is fixed. This paper contributes to the literature by incorporating oligopolistic competition into a general equilibrium model of economic geography and deriving results analytically. ${ }^{1}$ As the number of varieties in the manufacturing sector is

\footnotetext{
${ }^{1}$ One difficulty of incorporating oligopolistic competition into a general equilibrium framework is related to the following issue. A firm is both a seller of output and a buyer of labor input. To study the impact of a firm's market power in the output market, the number of firms in the output market should be small. However, a firm may also have market power in the factor market when the number of firms is small. A firm's market power in the factor market may complicate the study of market power in the product market. Neary (2003) and Ruffin (2003) have more detailed discussions of the possible strategies adopted in the literature in modeling oligopolistic competition in a general equilibrium framework. In this paper, there is a continuum of manufactured goods. Though each firm has market power in the industry it operates, a firm does not have market power in the factor market since the number of manufacturing industries is infinity.
} 
exogenously given, each variety or product is produced by multiple firms. There are two regions and each region has two sectors: agriculture and manufacturing. Agricultural technology exhibits constant returns to scale and manufacturing technologies exhibit increasing returns to scale. For firms producing the same manufactured goods, they engage in oligopolistic competition: each firm's optimal strategy depends on other firms' strategies. This kind of strategic interaction leads a firm's price and quantity of production to change with the environment it operates in. Except for the assumption of oligopolistic competition, other assumptions in this paper are similar to those in Krugman (1991).

We show that some results are robust regardless of whether the market structure is monopolistic competition or oligopoly. First, the real wage rate in terms of manufactured goods is higher and the real wage rate in terms of agricultural goods is lower in the region with a larger number of workers. Second, a higher propensity to spend on manufactured goods increases the propensity of agglomeration. Third, a higher elasticity of demand for manufactured goods makes agglomeration less likely to be stable.

The assumption of oligopolistic competition also leads to results significantly different from those based on monopolistic competition. First, the patterns of trade are different. In the monopolistic competition framework, a firm producing manufactured goods in the region with a lower population can sell its product to the region with a higher population because it is the only firm in the world producing this product. Regions engage in intra-industry trade. With oligopolistic competition, a firm producing manufactured goods in the region with a higher population has a higher scale of production, thus a lower average cost and a lower price. A firm producing manufactured goods in the region with a lower population will not be able to sell its product to the region with a higher population. Regions engage in inter-industry trade: the region with a larger amount of workers exports manufactured goods to the other one in exchange for agricultural products. Thus, there is no necessary connection between intra-industry and internal increasing returns to scale. 
Second, in Krugman (1991), to compare workers' utilities in the two regions, a price index is needed and this makes analytical results difficult to obtain and simulations are used to gain insights. $^{2}$ A price index is needed because some manufactured goods are transported from the region with a higher population to the region with a lower population and some other manufactured goods are transported in the opposite way. With oligopolistic competition, manufactured goods may be transported from the region with a higher population to the region with a lower population, but not the opposite way. As a price index is not needed, the oligopolistic competition approach is rich in analytical results.

Third and finally, in the monopolistic competition framework, firms in different regions have the same scale of production. In the oligopolistic competition framework, a firm's scale of production increases with the size of the market. In this paper, manufacturing firms located at different regions are not restricted to have the same technology. Different scales of production in different regions lead to choices of different technologies. Thus, another contribution of this paper is that this framework is conducive to the incorporation of the choice of technology as a channel of concentration of industries.

In principle, models based on monopolistic competition can generate the result that a firm's markup is not constant. For example, with linear demand, Ottaviano et al. (2002) also allow for different scales of production in different locations. However, Krugman (1991) and others have used the special utility function featuring constant elasticity of demand as the general utility function is not as tractable as the special one.

To our limited knowledge, there are very few empirical studies testing different implications between monopolistic competition and oligopolistic competition. One reason is that monopolistic competition is the primary paradigm used for theoretical studies with a general equilibrium structure. In reality, oligopolistic competition is a very important type of market

\footnotetext{
${ }^{2}$ Green (1964) has a detailed discussion of aggregation in economics.
} 
structure. Casual observation shows that many industries are dominated by a few large firms. For example, the market of large commercial aircraft is dominated by Airbus and Boeing. In their textbook, Pindyck and Rubinfeld (2005, p441) write "oligopoly is a prevalent form of market structure. Examples of oligopolistic industries include automobiles, steel, aluminum, petrochemicals, electrical equipment, and computers."

In the literature, Combes (1997) and Dewit et al. (2003) have studied economic geography based on oligopolistic competition. Their approaches and focuses are quite different from those in this paper. Combes (1997) assumes that markets are segregated rather than integrated. Dewit et al. (2003) are mainly interested in studying the use of labor standard as a commitment device when strategic interaction between firms is important.

The rest of the paper is organized as follows. Section 2 studies the equilibrium in which different regions are in autarky. The equilibrium with regional trade is studied in Section 3. Two possible channels for industries to concentrate in one region are examined in the next three sections. In Sections 4 and 5, factor movement may work as a channel for firms to concentrate in one region. In Section 4, there is no regional trade. In Section 5, there is regional trade. In Section 6, firms' optimal choices of their production technologies may act as the channel for firms to concentrate. Section 7 suggests some extensions of this line of research and concludes.

\section{REGIONS IN AUTARKY}

There are two regions: region 1 and region 2. Each region has two sectors: agriculture and manufacturing. There are two factors of production: farmers and workers. Farmers are specific to the agricultural sector. Workers are specific to the manufacturing sector, but they may move between firms producing different manufactured goods. In this section, there is neither trade of goods nor movement of factors of production between regions. The number of farmers in each

region is denoted by $L^{A}$. For $i=1,2$, the number of workers in region $i$ is $L_{i}$. In this paper, 
subscripts are frequently used to denote different regions (region 1 or region 2) and superscripts are frequently used to denote different sectors (agriculture or manufacturing). The analysis focuses on region 1 as the study of region 2 is similar. In the following, sometimes only notations for region 1 are explained as the notations for region 2 correspond to those for region 1.

Both regions have access to the same set of production technologies. It is assumed that the production technology of agricultural goods exhibits constant returns to scale. Without further loss of generality, it is assumed that one farmer produces one unit of agricultural goods. Thus, the output of agricultural goods in each region is $L^{A}$. The price of agricultural goods is normalized to 1: $p^{A} \equiv 1$. Following Dornbusch et al. (1977), there is a continuum of manufactured goods indexed by a number $\omega \in[0,1] .^{3}$ To produce each manufactured product, both a fixed cost and a marginal cost are needed. With the existence of fixed costs of production, there is increasing returns to scale in the manufacturing sector. All goods are symmetric in the sense that they have the same cost structure. To simplify analysis, we focus on a symmetric equilibrium. In a symmetric equilibrium, the price and the quantity of production of all the manufactured goods will be the same.

In the following, conditions for an equilibrium are studied. First, a consumer's utility maximization is studied. A consumer chooses the quantity of consumption to maximize her utility. Let $C_{1}^{A A}$ denote a region 1 farmer's consumption of agricultural goods and $C_{1}^{A M}$ denote this farmer's consumption of manufactured goods. For $\alpha$ and $\delta$ denoting positive constants, a farmer's utility function is given by $U^{A}=\left(C_{1}^{A A}\right)^{\alpha}\left(\int_{0}^{1}\left(C_{1}^{A M}(\omega)\right)^{\frac{\delta-1}{\delta}} d \omega\right)^{\frac{\delta(1-\alpha)}{\delta-1}}$. As firms make a profit of zero in equilibrium, consumers only have wage income. A farmer's budget constraint is

\footnotetext{
${ }^{3}$ Early on, Aumann (1964) has studied a model with a continuum of traders.
} 
given by $C_{1}^{A A}+\int_{0}^{1} p_{1}^{M}(\omega) C_{1}^{A M}(\omega) d \omega=1$. Let $C_{1}^{M A}$ denote a region 1 worker's consumption of agricultural goods and $C_{1}^{M M}$ denote this worker's consumption of manufactured goods. A region 1 worker's utility function is $U^{M}=\left(C_{1}^{M A}\right)^{\alpha}\left(\int_{0}^{1}\left(C_{1}^{M M}(\omega)\right)^{\frac{\delta-1}{\delta}} d \omega\right)^{\frac{\delta(1-\alpha)}{\delta-1}}$. The wage rate in region $i$ is $w_{i}$. Let $p_{i}^{m}$ denote the price of manufactured goods in region $i$. A region 1 worker's budget constraint is $C_{1}^{M A}+\int_{0}^{1} p_{1}^{M}(\omega) C_{1}^{M M}(\omega) d \omega=w_{1}$.

From a consumer's utility maximization, a consumer spends a fixed $\alpha$ percent of total income on agricultural goods and $1-\alpha$ percent of total income on manufactured goods. ${ }^{4}$ As there is a continuum of manufactured goods, a given manufactured product's share of total manufactured output is zero. As a result, farmers and workers' elasticities of demand are given by

$$
\begin{aligned}
& \frac{p_{1}^{M}}{C_{1}^{A M}} \frac{\partial C_{1}^{A M}}{p_{1}^{M}}=-\delta, \\
& \frac{p_{1}^{M}}{C_{1}^{M M}} \frac{\partial C_{1}^{M M}}{p_{1}^{M}}=-\delta .
\end{aligned}
$$

Second, a manufacturing firm's profit maximization is studied. A firm takes the wage rate as given and chooses its quantity of production to maximize its profit. A region $i$ firm's fixed cost in terms of the amount of labor needed is $f_{i}$ and its constant marginal cost in terms of the amount of labor needed is $\beta_{i}$. It is not necessary to require the costs of production in the two regions to be the same. For $x_{i}$ denoting a region $i$ manufacturing firm's quantity of production, this firm's profit is $p_{i}^{m} x_{i}-\left(f_{i}+\beta_{i} x_{i}\right) w_{i}$.

\footnotetext{
${ }^{4}$ Ottaviano et al. (2002) study a model of agglomeration in which the utility function is quadratic. In their paper, the percentage of income spent on a given product is not constant.
} 
In each region, for each product, there are multiple firms producing this homogeneous product. Let $m_{i}$ denote the number of manufacturing firms in region $i$ producing the same product. The number of firms belonging to a sector is a real number rather than an integer number. For firms producing the same product, they engage in Cournot competition. The first order condition for a region 1 firm's optimal output requires that

$$
p_{1}^{m}\left(1+\frac{x_{1}}{p_{1}^{m}} \frac{\partial p_{1}^{m}}{\partial x_{1}}\right)=\beta_{1} w_{1}
$$

Equation (1) is a familiar condition stating that the price charged by a firm depends on the elasticity of demand it faces. The elasticity of demand faced by a firm is different from a given consumer's elasticity of demand as there are other firms producing the same market.

Third, it is assumed that firms can freely enter and exit an industry. As a result, a firm makes a profit of zero. ${ }^{5}$ Zero profit for a manufacturing firm in region 1 requires that

$$
p_{1}^{m} x_{1}-\left(f_{1}+\beta_{1} x_{1}\right) w_{1}=0
$$

Fourth, labor market needs to be cleared. Each firm in region 1 demands $f_{1}+\beta_{1} x_{1}$ units of workers. Since the amount of manufacturing firms in region 1 is $m_{1}$, the total demand for workers in region 1 is $m_{1}\left(f_{1}+\beta_{1} x_{1}\right)$. As each worker supplies one unit of labor inelastically, the total supply of workers in region 1 is $L_{1}$. Equalization of demand and supply of labor in region 1 requires that

$$
m_{1}\left(f_{1}+\beta_{1} x_{1}\right)=L_{1}
$$

\footnotetext{
${ }^{5}$ Oligopolistic competition with fixed costs and free entry has been studied extensively in the literature on strategic trade, see Sections 3.7 and 4.5 of Brander (1995) for a review of this line of literature. Oligopolistic competition with free entry is also discussed in Mankiw and Whinston (1986).
} 
Fifth and finally, markets for manufactured and agricultural goods need to be cleared. For manufactured goods in region 1 , the total demand is $L^{A} C_{1}^{A M}+L_{1} C_{1}^{M M}$ and the total supply is $m_{1} x_{1}$. Equalization of demand and supply of manufactured goods in region 1 requires that

$$
L^{A} C_{1}^{A M}+L_{1} C_{1}^{M M}=m_{1} x_{1} \equiv x_{1}+x_{-1}
$$

where $x_{-1}$ denotes output from all other firms. A farmer's income is one and a region 1 worker's income is $w_{1}$. As a consumer spends $1-\alpha$ percent of income on manufactured goods, a farmer's demand of manufactured goods is $\frac{(1-\alpha)}{p_{1}^{m}}$ and a region 1 worker's demand is $\frac{(1-\alpha) w_{1}}{p_{1}^{m}}$. Thus, equation (5) leads to

$$
(1-\alpha)\left(\frac{L^{A}}{p_{1}^{m}}+\frac{L_{1} w_{1}}{p_{1}^{m}}\right)=m_{1} x_{1}
$$

The demand for agricultural goods in region 1 is $L^{A} C_{1}^{A A}+L_{1} C_{1}^{M A}$. As each farmer produces one unit of output, the supply of agricultural goods is $L^{A}$. Equalization of demand and supply of agricultural goods in region 1 requires that $L^{A} C_{1}^{A A}+L_{1} C_{1}^{M A}=L^{A}$. As a consumer spends $\alpha$ percent of income on agricultural goods, this leads to

$$
\alpha\left(L^{A}+w_{1} L_{1}\right)=L^{A} .
$$

In a Cournot equilibrium, for a firm choosing its output $x_{1}$, this firm views that $x_{-1}$ does not change when it adjusts $x_{1}$. Differentiation of both sides of equation (5) yields

$$
\begin{aligned}
\frac{\partial x_{1}}{\partial p_{1}^{m}}=L^{A} \frac{\partial C_{1}^{A M}}{\partial p_{1}^{m}} & +L_{1} \frac{\partial C_{1}^{M M}}{\partial p_{1}^{m}} \\
& =\frac{1}{p_{1}^{m}}\left(\frac{\partial C_{1}^{A M}}{\partial p_{1}^{m}} \frac{p_{1}^{m}}{C_{1}^{A M}} L^{A} C_{1}^{A M}+\frac{\partial C_{1}^{M M}}{\partial p_{1}^{m}} \frac{p_{1}^{m}}{C_{1}^{M M}} L_{1} C_{1}^{M M}\right)
\end{aligned}
$$


From (1a), (1b), (5), and (8), it can be shown that the elasticity of demand faced by a manufacturing firm is $\frac{p_{1}^{m} \partial x_{1}}{x_{1} \partial p_{1}^{m}}=-m_{1} \delta$. Plugging this elasticity into equation (2) leads to

$$
p_{1}^{m}=\frac{m_{1} \delta}{m_{1} \delta-1} \beta_{1} w_{1}
$$

As equation (9) is essential in understanding this framework of oligopolistic competition, it deserves some explanation. ${ }^{6}$ This equation shows that a firm's price as a markup over the marginal cost of production decreases with the number of firms producing the same product, which is endogenously determined by the extent of the market as measured by $L_{1}$. There are two special cases of this equation. First, if there is only one firm producing each product $\left(m_{1}=1\right)$, equation (9) degenerates to $p_{1}^{m}=\frac{\delta}{\delta-1} \beta_{1} w_{1}$, which is equation (5) in $\operatorname{Krugman}$ (1991, p. 489). Second, for perfect competition ( $m_{1}=\infty$ ), equation (9) shows that a firm's price equals marginal cost.

In a symmetric equilibrium, equations (3), (4), (6), (7), and (9) form a set of five equations defining five variables $m_{1}, w_{1}, x_{1}, p_{1}^{m}$, and $p^{A}$. This set of equations can be solved explicitly. Equation (7) yields

$$
w_{1}=\frac{(1-\alpha) L^{A}}{\alpha L_{1}} \text {. }
$$

The equilibrium values of other variables are given by

$$
\begin{aligned}
& x_{1}=\frac{\sqrt{f_{1} L_{1} \delta}-f_{1}}{\beta_{1}}, \\
& p_{1}^{m}=\frac{(1-\alpha) \beta_{1} L^{A}}{\alpha\left(L_{1}-\sqrt{f_{1} L_{1} / \delta}\right)},
\end{aligned}
$$

\footnotetext{
${ }^{6}$ Derivation of the elasticity of demand when firms engage in Cournot competition is illustrated in Zhou (2004, 2006).
} 


$$
m_{1}=\sqrt{\frac{L_{1}}{f_{1} \delta}} .
$$

From equations (11) and (13), both the number of manufacturing firms and a firm's quantity of production increase with the number of workers in a region. From (11), the degree of economies of scale measured by the ratio of the marginal product of labor to its average product equals $1-\sqrt{f_{1} /\left(\delta L_{1}\right)}$. Thus, the degree of economies of scale depends not only on the elasticity of substitution $\delta$, but also on the ratio of fixed cost to labor endowment $f_{1} / L_{1}$.

The following proposition studies the relationship between the real wage rate and the number of workers in a region.

Proposition 1: When regions are in autarky, a worker's wage rate in terms of agricultural goods decreases with the number of workers in a region. A worker's wage rate in terms of manufactured goods increases with the number of workers in a region.

Proof: Since the agricultural product is used as the numeraire, the first part of the proposition comes from equation (10). For the second part of the proposition, dividing equation (10) by (12) yields

$$
\frac{w_{1}}{p_{1}^{m}}=\frac{1-\sqrt{f_{1} /\left(\delta L_{1}\right)}}{\beta_{1}} .
$$

From (14), $w_{1} / p_{1}^{m}$ increases with $L_{1}$.

From Proposition 1, when each region is in autarky, a worker's wage rate in terms of manufactured goods increases with the number of workers in a region. The reason behind this is that a firm's scale of production increases with the number of workers. With the fixed cost of production, average cost decreases with output. As a firm makes a profit of zero, a lower average 
cost means a lower price. Thus, the real wage rate in terms of manufactured goods increases with the number of workers in a region.

Proposition 1 shows the tradeoff faced by a worker located in a region with a larger number of workers. With increasing returns to scale in the manufacturing sector, a worker's consumption of manufactured goods is higher. However, as the supply of agricultural goods is fixed, the consumption of agricultural goods is lower.

In Krugman (1991), a firm's output and the ratio of a firm's price to wage rate are not affected by the amount of labor in a region. However, as a region with a higher labor endowment produces a higher number of manufactured goods and locally produced manufactured goods are less expensive than imported manufactured goods because of the existence of transportation costs, the price index is lower in a region with a higher number of workers. In this sense, a worker's real wage rate in terms of manufactured goods is also higher in a region with a higher amount of labor. In addition, in monopolistic competition models, a worker's real wage rate in terms of agricultural goods is lower in a region with a higher amount of labor. Thus, a worker's real wage in terms of manufactured goods increases with the number of workers in a region and this worker's wage rate in terms of agricultural goods decreases with the number of workers in a region is a robust feature of alternative assumptions of market structure.

\section{TRADE BETWEEN REGIONS}

In this section, the equilibrium with regional trade is studied. Markets for manufactured goods in different regions are integrated. It is assumed that the transportation cost for agricultural goods is zero and the transportation cost for manufactured goods between the two regions is positive. ${ }^{7}$ Following Samuelson (1954), for $t$ denoting a positive constant, for each unit of

\footnotetext{
${ }^{7}$ Davis (1998) has shown that the assumption of zero transportation cost of agricultural goods may not be innocuous. With a positive transportation cost for agricultural goods, the price of agricultural goods for the region importing agricultural goods will be higher than the price in the region exporting agricultural goods. In this case, compared to the case of zero transportation cost, the equilibrium of equal number of workers in
} 
manufactured goods arrived, $1+t$ units of goods need to be sent out. If the transportation cost is too high, the two regions will not trade. The two regions begin to trade when the price difference of manufactured goods is large enough to cover transportation costs.

The total measure of workers in the two regions is exogenously given and is equal to $L$ : $L_{1}+L_{2}=L$. Without loss of generality, it is assumed that $L_{1} \geq L_{2} \cdot{ }^{8}$ From Proposition 1, if the two regions have the same production technology and $L_{1}>L_{2}$, region 1 has a lower price of manufactured goods. Thus, manufactured goods will be exported from region 1 to region 2 if transportation cost $t$ is small enough. The trade pattern is that region 1 exports manufactured goods to region 2 and imports agricultural goods from region $2 .{ }^{9}$ This result is summarized in Proposition 2.

Proposition 2: For regions with different amounts of workers, they engage in inter-industry trade.

Proposition 2 shows that increasing returns to scale does not necessarily lead to intraindustry trade. The key factor leading to this result of inter-industry trade is that with oligopolistic competition a firm's output increases with the extent of the market. With monopolistic competition, it is assumed that each variety is produced by only one firm in the world, intra-industry naturally arises. Both inter and intra industry trade are commonly observed in reality. Whether monopolistic competition or oligopolistic competition applies depends on the specific conditions

the two regions is more likely to be stable. The reason is as follows. Starting from an equal number of workers in the two regions, if a worker moves from region 1 to region 2, the price of agricultural goods in region 1 will be higher than that of region 2 . This decreases a region 1 worker's utility and decreases a worker's incentive to move into region 1.

${ }^{8}$ This may be the result that some random events cause region 1 to have a higher endowment of workers.

${ }^{9}$ In this paper, the markets of manufactured goods in the two regions are integrated rather than segmented. As a result, cross-hauling of manufactured goods between the two regions Brander (1981) will not occur. 
of an industry (such as the relative magnitude of fixed cost to the size of the market) and this can be addressed by empirical studies.

From the specification of the transportation technology, the relationship between the prices of manufactured goods in the two regions is given by

$$
p_{2}^{m}=(1+t) p_{1}^{m}
$$

Before trade, from (10), the wage rate in region 1 is lower than that in region 2. Regional trade leads to an increase of the wage rate in region 1 and a decrease of the wage rate in region 2. With the existence of transportation costs, regional trade will not lead to an equalization of the wage rate between the regions.

In the rest of this section, conditions for the equilibrium with regional trade are studied. First, for a firm in region 1, regardless of whether its output is sold in region 1 or transported to region 2 , the price received by this firm is $p_{1}^{m}$. A region $i$ firm's profit is $p_{i}^{m} x_{i}-\left(f_{i}+\beta_{i} x_{i}\right) w_{i}$ . Zero profit for a firm in region $i$ requires that

$$
p_{i}^{m} x_{i}-\left(f_{i}+\beta_{i} x_{i}\right) w_{i}=0, \text { for } i=1,2 \text {. }
$$

Second, equalization of demand and supply of labor in region $i$ requires that

$$
m_{i}\left(f_{i}+\beta_{i} x_{i}\right)=L_{i} \text {, for } i=1,2 \text {. }
$$

Third, equalization of demand and supply of agricultural goods requires that

$$
L^{A} C_{1}^{A A}+L_{1} C_{1}^{M A}+L^{A} C_{2}^{A A}+L_{2} C_{2}^{M A}=2 L^{A}
$$

As a consumer spends $\alpha$ percent of income on agricultural goods, the above equation leads to

$$
\alpha\left(2 L^{A}+w_{1} L_{1}+w_{2} L_{2}\right)=2 L^{A}
$$

Fourth, let $E$ denote the quantity of export of manufactured goods from region 1 and let $I$ denote the quantity of imported manufactured goods arrived at region 2 . The specification of transportation technology requires that $E=(1+t) I$. For manufactured goods in region 1 , the total 
demand is $L^{A} C_{1}^{A M}+L_{1} C_{1}^{M M}$ and the total supply is $m_{1} x_{1}-E$. Equalization of demand and supply of manufactured goods in region 1 requires that

$$
L^{A} C_{1}^{A M}+L_{1} C_{1}^{M M}=m_{1} x_{1}-E .
$$

As a consumer spends $1-\alpha$ percent of income on manufactured goods, the above equation leads

to

$$
(1-\alpha)\left(L^{A} \frac{1}{p_{1}^{m}}+L_{1} \frac{w_{1}}{p_{1}^{m}}\right)=m_{1} x_{1}-E .
$$

The supply of manufactured goods in region 2 is the sum of region 2 production $m_{2} x_{2}$ and import $I$. Equalization of demand and supply of manufactured goods in region 2 requires that

$$
L^{A} C_{2}^{A M}+L_{2} C_{2}^{M M}=m_{2} x_{2}+I
$$

As a consumer spends $1-\alpha$ percent of income on manufactured goods, equation (21) leads to

$$
(1-\alpha)\left(L^{A} \frac{1}{p_{2}^{m}}+L_{2} \frac{w_{2}}{p_{2}^{m}}\right)=m_{2} x_{2}+I
$$

Equations (19) and (21) yield

$$
L^{A} C_{1}^{A M}+L_{1} C_{1}^{M M}+(1+t)\left(L^{A} C_{2}^{A M}+L_{2} C_{2}^{M M}\right)=m_{1} x_{1}+(1+t) m_{2} x_{2} .
$$

Equations (20) and (22) yield

$$
\begin{gathered}
(1-\alpha)\left(L^{A} \frac{1}{p_{1}^{m}}+L_{1} \frac{w_{1}}{p_{1}^{m}}\right)+(1-\alpha)(1+t)\left(L^{A} \frac{1}{p_{2}^{m}}+L_{2} \frac{w_{2}}{p_{2}^{m}}\right) \\
=m_{1} x_{1}+(1+t) m_{2} x_{2} .
\end{gathered}
$$

Finally, as the markets for manufactured goods in the two regions are integrated, a manufactured firm will take the response of consumers in both regions into consideration when it chooses its output. From equation (23), the Cournot assumption leads to

$$
\frac{\partial x_{1}}{\partial p_{1}^{m}}=L^{A} \frac{\partial C_{1}^{A M}}{\partial p_{1}^{m}}+L_{1} \frac{\partial C_{1}^{M M}}{\partial p_{1}^{m}}+(1+t) L^{A} \frac{\partial C_{2}^{A M}}{\partial p_{1}^{m}}+(1+t) L_{2} \frac{\partial C_{2}^{M M}}{\partial p_{1}^{m}}
$$




$$
\begin{gathered}
=\frac{1}{p_{1}^{m}}\left(\frac{\partial C_{1}^{A M}}{\partial p_{1}^{m}} \frac{p_{1}^{m}}{C_{1}^{A M}} L^{A} C_{1}^{A M}+\frac{\partial C_{1}^{M M}}{\partial p_{1}^{m}} \frac{p_{1}^{m}}{C_{1}^{M M}} L_{1} C_{1}^{M M}\right) \\
+\frac{1}{p_{1}^{m}}\left(\frac{\partial C_{2}^{A M}}{\partial p_{2}^{m}} \frac{p_{2}^{m}}{C_{2}^{A M}}(1+t) L^{A} C_{2}^{A M}+\frac{\partial C_{2}^{M M}}{\partial p_{2}^{m}} \frac{p_{2}^{m}}{C_{2}^{M M}}(1+t) L_{2} C_{2}^{M M}\right) \\
=-\frac{\delta\left(m_{1} x_{1}+(1+t) m_{2} x_{2}\right)}{p_{1}^{m}} .
\end{gathered}
$$

Similarly, it can be shown that

$$
\frac{\partial x_{2}}{\partial p_{2}^{m}}=-\frac{\delta\left(m_{1} x_{1}+(1+t) m_{2} x_{2}\right)}{(1+t) p_{2}^{m}}
$$

Combining firms' optimal output choices with equations (25) and (26) yields

$$
\begin{aligned}
& p_{1}^{m}\left(1-\frac{x_{1}}{\delta\left(m_{1} x_{1}+(1+t) m_{2} x_{2}\right)}\right)=\beta_{1} w_{1}, \\
& p_{2}^{m}\left(1-\frac{(1+t) x_{2}}{\delta\left(m_{1} x_{1}+(1+t) m_{2} x_{2}\right)}\right)=\beta_{2} w_{2} .
\end{aligned}
$$

The interpretation of equations (27) and (28) is similar to that of equation (9). There are three comments on these two equations. First, the impact of an increase of one unit of output for a firm in region 2 is similar to that of an increase of $1+t$ units of output for a firm in region 1 . The reason is that $1+t$ units of output must be sent out from region 1 in order to have region 2 to receive one unit of output. Second, these equations show that a firm's price as a markup over marginal cost increases with a firm's market share. This is intuitive in the sense that a firm's market share is directly related to a firm's monopoly power. Third and finally, when there is no transportation cost and firms in different regions use the same production technologies, the two equations are symmetric.

Equations (15)-(18), (24), and (27)-(28) form a system of nine equations defining a system of nine variables $m_{1}, m_{2}, w_{1}, w_{2}, x_{1}, x_{2}, p_{1}^{m}, p_{2}^{m}$, and $p^{A}$. In the following, we study the 
equilibrium in which firms in the same region have the same level of output. Firms in different regions may have different levels of output.

\section{WORKER MOVEMENT WITHOUT TRADE}

Will the emigration of a worker increase other workers' incentive to emigrate? In this section and the next one, the impact of movement of workers across regions is studied. In this section, worker movement without regional trade is examined. The following proposition studies the stability of the equilibrium that the two regions have equal number of workers $L / 2$.

Proposition 3: The equilibrium that the two regions have equal number of workers is locally stable if and only if $\frac{L}{2 f_{1}}>\left(\frac{1+\alpha}{2 \alpha}\right)^{2} \frac{1}{\delta}$.

Proof: From (10), (12), and the specification of the utility function, a region 1 worker's utility is

$$
U^{M}=\frac{(1-\alpha)\left(L^{A}\right)^{\alpha}\left(L_{1}-\sqrt{f_{1} L_{1} / \delta}\right)^{1-\alpha}}{\left(\beta_{1}\right)^{1-\alpha} L_{1}}
$$

Differentiation of the above equation with respect to $L_{1}$ leads to

$$
\frac{d U^{M}}{d L_{1}}=\frac{(1-\alpha)\left(L^{A}\right)^{\alpha}\left(\frac{(1+\alpha)}{2} \sqrt{\frac{f_{1} L_{1}}{\delta}}-\alpha L_{1}\right)}{\left(\beta_{1}\right)^{1-\alpha}\left(L_{1}-\sqrt{\frac{f_{1} L_{1}}{\delta}}\right)^{\alpha}\left(L_{1}\right)^{2}} .
$$

Thus, whether $\frac{d U^{M}}{d L_{1}}<0$ or not depends on whether $\frac{L}{2 f_{1}}>\left(\frac{1+\alpha}{2 \alpha}\right)^{2} \frac{1}{\delta}$ or not.

Q.E.D.

When there is no regional trade, moving to a region with a larger population leads to two effects working on opposite directions. The benefit comes from the lower price of manufactured 
goods. The cost comes from a lower level of consumption of agricultural goods. Thus, whether the equilibrium is stable or not depends on the magnitude of the two effects. Proposition 3 shows that the equilibrium with equal number of workers in the two regions is less likely to be stable if $L / f_{1}, \delta$, or $\alpha$ increases. First, if $L / f_{1}$ is already large, when a worker moves to a region with a larger population, the decrease of the price of manufactured goods in this region will be small. That is, the benefit from a decrease of the price of manufactured goods is small. Second, a higher elasticity of demand $\delta$ decreases the number of firms producing the same product. Third and finally, for a larger value of $\alpha$, a consumer spends a large amount of income on agricultural goods, this increases the cost of moving to an area with a larger population.

\section{WORKER MOVEMENT WITH TRADE}

In this section, worker movement with regional trade is examined.

The following proposition studies the condition for a region 1 firm to move to region 2 and make a nonnegative profit if all workers currently live in region 1 . The proof contains two steps. First, when all workers are in region 1, the wage rate and the price of manufactured goods in region 1 are expressed as functions of exogenous parameters. Second, the condition for a worker moving to region 2 to have a higher utility than a worker staying in region 1 is studied.

Proposition 4: The configuration in which all workers concentrate in one region is an equilibrium if and only if

$$
v \equiv 1-\frac{\beta_{2}}{\beta_{1}} \frac{\left(1-\sqrt{f_{1} /(\delta L)}\right)}{(1+t)^{\alpha}}-\frac{2 f_{2}(1+t)^{1-\alpha}}{L}<0 .
$$

Proof: First, when all workers are in region 1, the following equations hold,

$$
\begin{aligned}
& p_{1}^{m} x_{1}-\left(f_{1}+\beta_{1} x_{1}\right) w_{1}=0 \\
& m_{1}\left(f_{1}+\beta_{1} x_{1}\right)=L
\end{aligned}
$$




$$
\begin{aligned}
& \alpha\left(2 L^{A}+w_{1} L\right)=2 L^{A}, \\
& (1-\alpha)\left(2 L^{A}+w_{1} L\right)=p_{1}^{m} m_{1} x_{1}, \\
& p_{1}^{m}\left(1-\frac{1}{\delta m_{1}}\right)=\beta_{1} w_{1} .
\end{aligned}
$$

Equation (30) comes from the equalization of demand and supply of workers in region 1. Equation (31) comes from clearance of the market for agricultural goods. For equation (32), the left-hand side is the demand for manufactured goods and the right-hand side is the supply of manufactured goods. Equation (33) comes from a region 1 manufacturing firm's optimal output choice. Solving this set of equations yields

$$
\begin{aligned}
& w_{1}=\frac{2(1-\alpha) L^{A}}{\alpha L}, \\
& p_{1}^{m}=\frac{2(1-\alpha) \beta_{1} L^{A}}{\alpha L\left(1-\sqrt{f_{1} /(\delta L)}\right)} .
\end{aligned}
$$

Second, for a firm to attract workers to region 2 , it has to make sure that the utility of a worker in region 2 is not lower than a worker's utility in region 1 . For $p_{2}^{m}=(1+t) p_{1}^{m}$, from the utility function, the lowest wage rate $w_{2}$ for a worker in region 2 to have a utility not lower than a worker's utility in region 1 is

$$
w_{2}=(1+t)^{1-\alpha} w_{1}
$$

A firm moving to region 2 can make a nonnegative profit if and only if

$$
p_{2}^{m} x_{2}-\left(f_{2}+\beta_{2} x_{2}\right) w_{2} \geq 0
$$

Demand for this firm comes from workers employed in this firm and farmers in this region. The number of workers in this firm is $f_{2}+\beta_{2} x_{2}$ and their total income is $\left(f_{2}+\beta_{2} x_{2}\right) w_{2}$. Region 2 farmers' income is $L^{A}$. As each consumer spends $1-\alpha$ percent of income on manufactured goods, $p_{2}^{m} x_{2}=(1-\alpha)\left(\left(f_{2}+\beta_{2} x_{2}\right) w_{2}+L^{A}\right)$. Rearrangement of this equation yields 


$$
x_{2}=(1-\alpha) \frac{f_{2} w_{2}+L^{A}}{p_{2}^{m}-(1-\alpha) w_{2} \beta_{2}} .
$$

Plugging (15), (36), and (38) into (37) leads to (29).

Results in Proposition 4 are consistent with those in Proposition 3. From Proposition 4, first, an increase of the fixed cost $f_{1}$ or the marginal cost $\beta_{1}$ (a decrease of $f_{2}$ or $\beta_{2}$ ) makes concentration of workers in region 1 less likely to be an equilibrium. This fits our intuition well. Second, $d v / d \alpha>0$. Thus, a higher propensity to spend on manufactured goods makes the concentration more likely to be an equilibrium. The reason is that as a higher percentage of income is spent on imported manufactured goods, moving to a region with a lower population becomes costlier. Third, $d v / d \delta<0$. That is, a higher elasticity of substitution makes the concentration less likely to be an equilibrium. The intuition behind this result is clear from equations (11) and (14). From (11), a firm's scale of production increases with a consumer's elasticity of demand $\delta$ . From (14), the real wage rate in terms of the price of manufactured goods increases with $\delta$. That is, a higher $\delta$ increases the real wage rate in region 1 and makes moving to region 2 less attractive. Fourth and finally, the impact of transportation cost on the stability of concentration is ambiguous. The reason is that a higher transportation cost leads to two effects working on opposite directions. On the one hand, it increases a region 2 firm's market power and increases a defecting firm's profit. On the other hand, it makes the imported manufactured goods more expensive and a defecting firm must pay a higher wage rate to its workers.

The results here that a higher propensity to spend on manufactured goods and a lower elasticity of demand for manufactured goods make agglomeration more likely are consistent with results in Krugman (1991). Thus, those results are robust under alternative assumptions of market structure. 
The system of equations (15)-(18), (24), and (27)-(28) defining the trade equilibrium can be simplified into the following three equations:

$$
\begin{aligned}
& V_{1} \equiv \alpha\left(w_{1} L_{1}+w_{2} L_{2}\right)-2 L^{A}(1-\alpha)=0, \\
& V_{2} \equiv\left(\frac{p_{1}^{m}}{p_{1}^{m}-\beta_{1} w_{1}}\right)^{2} \alpha f_{1} w_{1}-2 \delta(1-\alpha) L^{A}=0, \\
& V_{3} \equiv\left(\frac{(1+t) p_{1}^{m}}{(1+t) p_{1}^{m}-\beta_{2} w_{2}}\right)^{2} \alpha f_{2} w_{2}-2 \delta(1-\alpha) L^{A}=0 .^{10}
\end{aligned}
$$

These three equations define three variables $w_{1}, w_{2}$, and $p_{m}^{1}$ as functions of exogenously given variables. The following proposition studies the implications of the immigration of a worker into region 1 when there is regional trade. ${ }^{11}$

Proposition 5: When a worker moves from region 2 to region 1, the wage rates in the two regions increase, and the prices of manufactured goods decrease.

Proof: Differentiation of $V_{1}, V_{2}$, and $V_{3}$ with respect to $w_{1}, w_{2}, p_{1}^{m}$, and $L_{1}$ leads to

\footnotetext{
${ }^{10}$ Equations (39)-(41) are derived in the following way. First, equation (39) comes from equation (18). Second, from (16), $x_{1}=\frac{f_{1} w_{1}}{p_{1}^{m}-\beta_{1} w_{1}}$. Plugging this value of $x_{1}$ and the value of $m_{1} x_{1}+(1+t) m_{2} x_{2}$ from (24) into equation (27) leads to equation (40). Finally, equation (41) is derived in a way similar to the derivation of (40).

${ }^{11}$ The method of proving Proposition 5 can also be used to study the impacts of a change of transportation cost on the wage rates and the prices of manufactured goods. By differentiating $V_{1}, V_{2}$, and $V_{3}$ with respect to $w_{1}, w_{2}, p_{1}^{m}$, and $t$, it can be shown that a higher transportation cost decreases the wage rate in region 1 and increases the wage rate in region 2. An increase in transportation cost decreases the price of manufactured goods in region 1 and the impact on the price of manufactured goods in region 2 is ambiguous. The reason is that a higher transportation cost decreases the competitiveness and thus the price of region 1 manufactured goods. As the price of manufactured goods in region 2 is transportation cost inclusive, the total effect is ambiguous.
} 


$$
\left(\begin{array}{ccc}
\frac{\partial V_{1}}{\partial w_{1}} & \frac{\partial V_{1}}{\partial w_{2}} & 0 \\
\frac{\partial V_{2}}{\partial w_{1}} & 0 & \frac{\partial V_{2}}{\partial p_{1}^{m}} \\
0 & \frac{\partial V_{3}}{\partial w_{2}} & \frac{\partial V_{3}}{\partial p_{1}^{m}}
\end{array}\right)\left(\begin{array}{l}
d w_{1} \\
d w_{2} \\
d p_{1}^{m}
\end{array}\right)=\left(\begin{array}{c}
-\frac{\partial V_{1}}{\partial L_{1}} d L_{1} \\
0 \\
0 \\
\end{array}\right) .
$$

Define

$$
\begin{aligned}
& \Delta \equiv-\frac{\partial V_{1}}{\partial w_{2}} \frac{\partial V_{2}}{\partial w_{1}} \frac{\partial V_{3}}{\partial p_{1}^{m}}-\frac{\partial V_{1}}{\partial w_{1}} \frac{\partial V_{2}}{\partial p_{1}^{m}} \frac{\partial V_{3}}{\partial w_{2}} \\
& \Delta_{1} \equiv \frac{\partial V_{1}}{\partial L_{1}} \frac{\partial V_{2}}{\partial p_{1}^{m}} \frac{\partial V_{3}}{\partial w_{2}} \\
& \Delta_{2} \equiv \frac{\partial V_{1}}{\partial L_{1}} \frac{\partial V_{2}}{\partial w_{1}} \frac{\partial V_{3}}{\partial p_{1}^{m}} \\
& \Delta_{3} \equiv \frac{\partial V_{1}}{\partial L_{1}} \frac{\partial V_{2}}{\partial w_{1}} \frac{\partial V_{3}}{\partial w_{2}}
\end{aligned}
$$

From the above definition, $\Delta$ is the determinant of the coefficient matrix. From (39), $\frac{\partial V_{1}}{\partial L_{1}}<0, \frac{\partial V_{1}}{\partial w_{1}}>0$, and $\frac{\partial V_{1}}{\partial w_{2}}>0$. From (40), $\frac{\partial V_{2}}{\partial w_{1}}>0$ and $\frac{\partial V_{2}}{\partial p_{1}^{m}}<0$. From (41), $\frac{\partial V_{3}}{\partial w_{2}}>0$ and $\frac{\partial V_{3}}{\partial p_{1}^{m}}<0$. Thus, $\Delta>0, \Delta_{1}>0, \Delta_{2}>0$, and $\Delta_{3}<0$. Application of Cramer's rule leads to $\frac{d w_{1}}{d L_{1}}=\frac{\Delta_{1}}{\Delta}, \frac{d w_{2}}{d L_{1}}=\frac{\Delta_{2}}{\Delta}$, and $\frac{d p_{1}^{m}}{d L_{1}}=\frac{\Delta_{3}}{\Delta}$. This leads to $d w_{1} / d L_{1}>0, d w_{2} / d L_{1}>0$, and $d p_{1}^{m} / d L_{1}<0$ Q.E.D.

The intuition behind Proposition 5 is as follows. An increase in the number of workers in region 1 leads to an increase of a manufacturing firm's output in this region. As the scale of production increases, average cost decreases and the price of manufactured goods in region 1 
decreases. From (15), the price of manufactured goods in region 2 also decreases. To break even, a manufacturing firm in region 2 responds by increasing its level of output. This expansion of output is possible as the number of manufacturing firms in region 2 shrinks. As a region 2 firm's output increases, the wage rate in region 2 also increases.

As wage rates in both regions increase, how relative wage rate changes is unclear. To address this question, how the wage ratio changes with factor movement is examined. Define the wage ratio between the two regions as $w \equiv w_{1} / w_{2}$. A worker's incentive to move is affected by the difference between the real wage rates in the two regions. As all manufactured goods are exported from region 1 to region 2, a price index for manufactured goods is not needed to study a worker's incentive to move. From equation (15), the prices of manufactured goods in the two regions differ only by a positive constant. So the difference between $w_{1} / w_{2}$ and $\left(w_{1} / p_{1}\right) /\left(w_{2} / p_{2}\right)$ is also a constant. Thus, the ratio of nominal wages provides the needed information to study a worker's incentive to move. The following proposition studies how the wage ratio changes with factor movement.

Proposition 6: When a worker moves from region 2 to region 1, if the two regions have the same technologies, the wage ratio increases.

Proof: Rearrangement of equation (39) yields

$$
L^{A}=\frac{\alpha\left(w_{1} L_{1}+w_{2} L_{2}\right)}{2(1-\alpha)} .
$$

Rearrangement of equation (40) yields

$$
p_{1}^{m}=\frac{\beta_{1} w_{1}}{1-\sqrt{\frac{\alpha f_{1} w_{1}}{2(1-\alpha) \delta L^{A}}}}
$$


Plugging equations (42) and (43) into (41) yields the following equation defining $w$ implicitly: $G \equiv\left(1-\sqrt{\frac{f_{2}}{\delta\left(w L_{1}+L_{2}\right)}}\right)(1+t) \beta_{1} w-\left(1-\sqrt{\frac{f_{1} w}{\delta\left(w L_{1}+L_{2}\right)}}\right) \beta_{2}=0$. This equation leads to

$$
\begin{gathered}
\frac{\partial G}{\partial w}>0 \\
\frac{\partial G}{\partial L_{1}}=\frac{1}{2} w(w-1)\left[\delta\left(w L_{1}+L_{2}\right)\right]^{-3 / 2}\left((1+t) \beta_{1} \sqrt{f_{2}}-\frac{\beta_{2} \sqrt{f_{1}}}{\sqrt{w}}\right) . \\
\text { For } \beta_{1}=\beta_{2} \text { and } f_{1}=f_{2}, \partial G / \partial L_{1}<0 . \text { Since } \frac{d w}{d L_{1}}=-\frac{\partial G / \partial L_{1}}{\partial G / \partial w}, d w / d L_{1}>0 \text { if the }
\end{gathered}
$$

two regions have the same production technologies.

Q.E.D.

Proposition 6 shows that movement of factors of production may act as a channel of concentration of industries. The intuition behind Proposition 6 is as follows. If firms in different regions have the same fixed and marginal costs, the percentage of output expansion for a manufacturing firm in region 1 is higher than that for a firm in region 2 when the price of manufactured goods in region 1 decreases. ${ }^{12}$ The reason is that the lower price of manufactured goods in region 1 leads to a lower profit margin per unit in region 1. A higher level of output leads to a lower average cost and a higher real wage rate.

\section{CHOICE OF PRODUCTION TECHNOLOGY}

\footnotetext{
${ }^{12}$ The following is a numerical example. Suppose that the price of manufactured goods in region 1 is 2 , a firm's marginal cost is 1 , and the fixed cost is 10 . A manufactured firm in region 1 needs to produce 10 units of output to make a profit of zero. Suppose that $50 \%$ of the goods transported arrive. Thus, the price of manufactured goods in region 2 is 3 and a firm in region 2 needs to produce 5 units of output to make a profit of zero. Now suppose the price of manufactured goods in region 1 decreases to 1.5. A firm in region 1 needs to produce 20 units of output to make a profit of zero, an increase of $100 \%$. The price of manufactured goods in region 2 will be 2.25 and a firm in region 2 needs to produce 8 units of output to make a profit of zero, an increase of $60 \%$, which is lower than $100 \%$.
} 
In reality, firms located in different regions with different market sizes may use different production technologies. According to Young (1928), the reason that the real wage rate in England is lower than that in the US is not because the entrepreneurs in the US are smarter or more industrious than their UK counterparts, but because the larger size of the US market leads entrepreneurs in the US to adopt technologies more suitable for larger scale of production. ${ }^{13}$ These larger scale production technologies lead to a lower average cost and a higher wage rate in the US. This section briefly discusses firms' optimal choices of their production technologies. ${ }^{14}$

It is assumed that there exists a continuum of technologies, indexed by $n$. A higher level of $n$ means a more advanced technology. For $f(n)$ denoting the fixed cost and $\beta(n)$ denoting the marginal cost in terms of the amount of labor needed associated with technology level $n$, it is assumed that $f^{\prime}(n)>0$ and $\beta^{\prime}(n)<0$. That is, the fixed cost of production increases with $n$, and the marginal cost of production decreases with $n$. A region $i$ firm's level of technology is denoted by $n_{i}$. A firm's profit is $p_{i}^{m} x_{i}-\left(f\left(n_{i}\right)+\beta\left(n_{i}\right) x_{i}\right) w_{i}$, for $i=1,2$. A firm chooses its production technology optimally. The first order condition for a firm's optimal choice of technology is $f^{\prime}\left(n_{i}\right)+\beta^{\prime}\left(n_{i}\right) x_{i}=0$. The second order condition requires that $-\left(f^{\prime \prime}\left(n_{i}\right)+\beta^{\prime \prime}\left(n_{i}\right) x_{i}\right)<0$. From the first and the second order conditions for a firm's profit maximization, a firm's optimal level of technology increases with its scale of production as a more advanced technology leads to a lower average cost for a larger scale of production.

Suppose a region has a higher number of workers than the other one. Firms in this region will adopt more advanced technologies as their scales of production are larger. This leads to a

\footnotetext{
${ }^{13}$ According to Young (1928, p. 530), "Mr. Ford's methods would be absurdly uneconomical if his output were very small, and would be unprofitable even if his output were what many other manufacturers of automobiles would call large."

${ }^{14}$ Ederington and McCalman (2004) have studied a model of technology choice in which firms engage in monopolistic competition. A common feature between their model and this one is that a firm's optimal technology is affected by its level of output. Zhou (2007) studies the implications of choice of technology in an open economy model. It is shown that the choice of technology acts as a link between external and internal increasing returns to scale.
} 
lower average cost and thus a higher real wage rate as a firm makes a profit of zero. A higher real wage rate in this region provides incentives for the immigration of workers from the other region. This leads to an even higher number of workers and an even more advanced technology. The above process forms a circular causation and the choice of technology acts as a channel of concentration of industries.

\section{CONCLUSION}

This paper studies a general equilibrium model of economic geography based on oligopolistic competition. It is shown that some results derived under monopolistic competition are robust under oligopolistic competition. First, the real wage rate in terms of manufactured goods is higher and the real wage rate in terms of agricultural goods is lower in the region with a larger number of workers. Second, a higher propensity to spend on manufactured goods and a lower elasticity of demand for manufactured goods make agglomeration more likely.

This framework of oligopolistic competition is conducive to analytical results. Oligopolistic competition leads to a manufacturing firm's output adjusts to the size of the market. This type of output adjustment has important implications. First, as firms in different regions have different levels of output, even with increasing returns, regions engage in inter-industry trade. Second, adjustment of output leads to the result that factor movement affects the wage ratio monotonically. Third and finally, manufacturing firms with different levels of output may choose different technologies. Choice of appropriate technology may act as a channel of concentration of industries.

There are some interesting generalizations of the model. First, as firms in different regions are not required to have the same production technology, this framework may be used to study regions with different levels of technological spillovers. Technological spillovers can be very important in affecting the concentration of some research-intensive firms in a region. Second, if the elasticity of demand for agricultural products decreases with income, concentration of industries 
is more likely than the case in which a fixed percentage of income is spent on agricultural goods.

The reason is that the benefit of living in a region with a lower price of manufactured goods is larger if the spending on manufactured goods increases with income. Third and finally, to address the endogenous development of technologies, extending the model to a dynamic setup may be an interesting avenue for future research.

\section{REFERENCES}

Aumann, Robert. 1964. Markets with a Continuum of Traders. Econometrica 32, 39-50.

Brander, James. 1981. Intra-Industry Trade in Identical Commodities. Journal of International Economics 11, 1-14.

Brander, James. 1995. "Strategic Trade Policy," in Gene Grossman and Kenneth Rogoff (Eds.), Handbook of International Economics. Volume 3, Amsterdam: North-Holland, pp. 1395-1455.

Combes, Pierre-Philippe. 1997. Industrial Agglomeration under Cournot Competition. Annales d'Économie et de Statistique 45, 161-182.

Davis, Donald. 1998. The Home Market, Trade, and Industrial Structure. American Economic Review 88, 1264-1276.

Dewit, Gerda, Dermot Leahy, and Catia Montagna. 2003. Employment Protection and Globalization in Dynamic Oligopoly. Working paper, University College Durbin.

Dornbusch, Rudiger, Stanley Fischer, and Paul Samuelson. 1977. Comparative Advantage, Trade, and Payments in a Ricardian Model with a Continuum of Goods. American Economic Review 67, 823-839.

Ederington, Josh, and Phillip McCalman. 2004. Endogenous Firm Heterogeneity and the Dynamics of Trade Liberalization. Working paper, University of California, Santa Cruz.

Green, H. A. John. 1964. Aggregation in Economic Analysis. Princeton, NJ: Princeton University Press. 
Head, Keith, and Thierry Mayer. 2004. "The Empirics of Agglomeration and Trade," in J. V. Henderson and J. F. Thisse (eds.), Handbook of Regional and Urban Economics: Cities and Geography. Volume 4, Amsterdam: North-Holland, pp. 2609-26609.

Krugman, Paul. 1991. Increasing Returns and Economic Geography. Journal of Political Economy 99, 483-499.

Mankiw, N. Greogry, and Michael Whinston. 1986. Free Entry and Social Inefficiency. Rand Journal of Economics 17, 48-58.

Neary, J. Peter. 2001. Of Hype and Hyperbolas: Introducing the New Economic Geography. Journal of Economic Literature 39, 536-561.

Neary, J. Peter. 2003. "The Road Less Traveled: Oligopoly and Competition Policy in General Equilibrium," in R. Arnott, B. Greenwald, R. Kanbur and B. Nalebuff (eds.), Economics for An Imperfect World: Essays in Honor of Joseph E. Stiglitz. Cambridge, Massachusetts: MIT Press, pp. 485-500.

Ottaviano, Gianmarco, Takatoshi Tabuchi, and Jacques-FranAois Thisse. 2002. Agglomeration and Trade Revisited. International Economic Review 43, 403-435.

Pindyck, Robert, and Daniel Rubinfeld. 2005. Microeconomics. sixth edition, Upper Saddle River, New Jersey: Pearson Education.

Porter, Michael. 1990. The Comparative Advantage of Nations. New York: Free Press.

Ruffin, Roy. 2003. Oligopoly and Trade: What, How much, and for Whom? Journal of International Economics 69, 315-335.

Samuelson, Paul. 1954. The Transfer Problem and Transport Costs, II: Analysis of Effects of Trade Impediments. Economic Journal, 64, 264-289.

Young, Allyn. 1928. Increasing Returns and Economic Progress. Economic Journal 38, 527-542.

Zhou, Haiwen. 2004. The Division of Labor and the Extent of the Market. Economic Theory 24, 195-209. 
Zhou, Haiwen. 2006. Intra-firm Specialization, Income Distribution, and International Trade. Journal of Economic Integration 21, 577-592.

Zhou, Haiwen, 2007. Increasing Returns, the Choice of Technology, and the Gains from Trade. Southern Economic Journal 74, 581-600. 